\title{
THE GROWTH STOP PHENOMENON OF BAOBABS (ADANSONIA SPP.) IDENTIFIED BY RADIOCARBON DATING
}

\author{
Adrian Patrut $^{1 *} \cdot$ Stephan Woodborne $^{2} \cdot$ Karl F von Reden $^{3} \cdot$ Grant Hall $^{4} \cdot$ \\ Roxana T Patrut ${ }^{5} \cdot$ Laszlo Rakosy $^{5} \cdot$ Pascal Danthu $^{6,7} \cdot$ Jean-Michel Leong Pock-Tsy $^{7} \bullet$ \\ Daniel A Lowy ${ }^{8} \cdot$ Dragos Margineanu $^{1}$ \\ ${ }^{1}$ Babeş-Bolyai University, Faculty of Chemistry, Cluj-Napoca, Romania. \\ ${ }^{2}$ iThemba LABS, Private Bag 11, WITS 2050, South Africa. \\ ${ }^{3}$ NOSAMS Facility, Dept. of Geology \& Geophysics, Woods Hole Oceanographic Institution, Woods Hole, \\ MA, USA. \\ ${ }^{4}$ Mammal Research Institute, University of Pretoria, South Africa. \\ ${ }^{5}$ Babeş-Bolyai University, Faculty of Biology and Geology, Cluj-Napoca, Romania. \\ ${ }^{6}$ DP Forêt et Biodiversité, Antananarivo, Madagascar. \\ ${ }^{7}$ Cirad, UPR BSEF, Montpellier, France. \\ ${ }^{8}$ Nova University, Alexandria Campus, Alexandria, VA, USA.
}

\begin{abstract}
The article reports the growth stop phenomenon, which was documented only for baobabs, i.e. for trees belonging to the Adansonia genus. The identification of growth stop was enabled by radiocarbon dating, which allows a complex investigation of samples collected from the trunk/stems of baobabs. In several cases, the outermost rings of baobabs, which were close to the bark, were found to be old, with ages of several hundreds of years, instead of being very young. Dating results of samples collected from six baobabs are presented. For multistemmed baobabs, the growth stop may occur only for one or several stems. We identified four factors that may induce the growth stop: (i) stress determined by severe climate conditions, (ii) old age, (iii) the need to keep a stable internal architecture, and (iv) the collapse of stems that survive this trauma. Baobabs and their stems affected by growth stop may survive for several centuries, by continuing to produce leaves, flowers, and fruits. This phenomenon was associated with the capacity of baobabs to store large amounts of water in their trunks/stems in the rainy season. This reservoir of water is used during the dry season and allows the trees to survive prolonged drought periods.
\end{abstract}

KEYWORDS: radiocarbon dating, AMS, tropical trees, age determination, growth stop.

\section{INTRODUCTION}

The genus Adansonia belonging to the Bombacoideae, a subfamily of Malvaceae, consists of nine species. Two species originate from mainland Africa, six are endemic to Madagascar, and one can be found only in northern Australia (Wickens 1983; Baum 1995; Wickens and Lowe 2008; Pettigrew et al. 2013).

In 2005, we started an in-depth research program to elucidate several controversial or poorly understood aspects related to the architecture, growth, and age of the African baobab (Adansonia digitata L.). This research is based on our new approach to investigate and date standing and live specimens. The methodology consists of accelerator mass spectrometry (AMS) radiocarbon dating of small wood samples, collected especially from inner cavities and/ or from deep incisions/entrances in the stems and from the outer part of baobabs (Patrut et al. $2007,2010 b, 2011)$. Due to the special ability of baobabs to produce stems periodically during their lifecycle, over time they develop architectures of increasing complexity. The obtained results have demonstrated that all large baobabs, with a girth of over $16 \mathrm{~m}$, are multistemmed. We identified the so-called open and closed ring-shaped structures, which are the most important architectures that enable African baobabs to reach old ages and large sizes. We also documented the presence of false cavities, which are large natural empty spaces between fused stems disposed in a closed ring-shaped structure. The oldest dated A. digitata individuals were found to have ages greater than $2000 \mathrm{yr}$ (Patrut et al. 2010c, 2013, 2015a, 2015d). Dated growth

\footnotetext{
*Corresponding author. Email: apatrut@gmail.com.
} 
rings of several studied African baobab specimens, which may act as a proxy climate archive, were used for past climate reconstruction in southern Africa (Robertson et al. 2006; Woodborne et al. 2015, 2016).

We extended our research on the architecture, growth, and age of the Adansonia genus by starting to investigate using the same approach on large individuals of the most representative three Malagasy species, namely the fony baobab (Adansonia rubrostipa Jum. \& H. Perrier), the za baobab (Adansonia za Baill.), and the Grandidier's baobab or Reniala (Adansonia grandidieri Baill.) (Baum 1996; Patrut et al. 2015b, 2015c, 2016). We found that their characteristic features, as assessed by AMS ${ }^{14} \mathrm{C}$ dating, are similar to those of the African baobab.

One should mention that the identification of very complex architectures and the accurate dating of large and old baobabs are not possible by means of traditional dendrochronological methods, which are based on tree-ring investigation. The existence of growth rings in African baobabs has generated much controversy (Guy 1970; Patrut et al. 2007, 2016; Wickens and Lowe 2008). We used ${ }^{14} \mathrm{C}$ dating to determine age sequences along wood samples collected from different baobabs, which were compared against growth ring counts. Results indicate that baobabs (Adansonia spp.) produce distinct growth rings that correspond in many cases to one rainy season, i.e. to $1 \mathrm{yr}$ in the investigated regions. However, in a sufficient number of cases, particularly in old baobabs, we found an anomalous ring frequency. For such cases, the number of rings between two dated segments of a sample was found to be significantly lower or significantly higher than the calendar age determined by ${ }^{14} \mathrm{C}$ dating. That is why the determination of stem ages and growth rates of large and old baobabs mandates the use of AMS ${ }^{14} \mathrm{C}$ dating of wood samples collected from determined positions. In such cases, ring counting and ring width analysis are not effective (Patrut et al. 2016). On the other hand, for certain baobabs the outermost rings were found to be old, with ages of several hundreds of years, instead of being very young. Such results show that baobab stems can stop growing due especially to old age or stress factors. Here, we present ${ }^{14} \mathrm{C}$ dating results that demonstrate the existence of the "growth stop" phenomenon in Adansonia species.

\section{MATERIAL AND METHODS}

\section{The Baobabs and Their Location}

We investigated six baobabs belonging to the $A$. digitata species. Two African baobabs, which were single-stemmed, died naturally in South Africa over the past years. These trees are the following:

The Pafuri Outpost baobab [Outpost area, Pafuri section, Kruger National Park (NP), Limpopo, South Africa; GPS coordinates $22^{\circ} 26.647^{\prime} \mathrm{S}, 031^{\circ} 04.745^{\prime} \mathrm{E}$, altitude $200 \mathrm{~m}$, annual rainfall $424 \mathrm{~mm}$ ] fell over and died in 2008 (Figures 1 and 2). It had a height of $18.0 \mathrm{~m}$, a circumference at breast height (cbh; at $1.30 \mathrm{~m}$ above ground) of $14.20 \mathrm{~m}$, and an overall wood volume of $\sim 60 \mathrm{~m}^{3}$. Pafuri Outpost was one of the largest single-stemmed African baobabs.

The Leokwe-A baobab (Leokwe camp, Mapungubwe NP, Limpopo, South Africa; $22^{\circ} 15.834^{\prime} \mathrm{S}$, $031^{\circ} 16.614^{\prime} \mathrm{E}, 579 \mathrm{~m}, 366 \mathrm{~mm}$ ) fell between 2003 and 2008 , when it was found toppled but intact. It had a circumference of around $7-8 \mathrm{~m}$.

The other four investigated $A$. digitata are of large size, possess multistemmed trunks, and are, with one exception, alive (even if some of their older stems died). These individuals are as follows:

The historic Chapman baobab (Ntwetwe Pan, Makgadikgadi Pans, Central, Botswana; $20^{\circ} 29.404^{\prime} \mathrm{S}, 025^{\circ} 14.971^{\prime} \mathrm{E}, 907 \mathrm{~m}, 360 \mathrm{~mm}$ ) had an open ring-shaped structure consisting of 


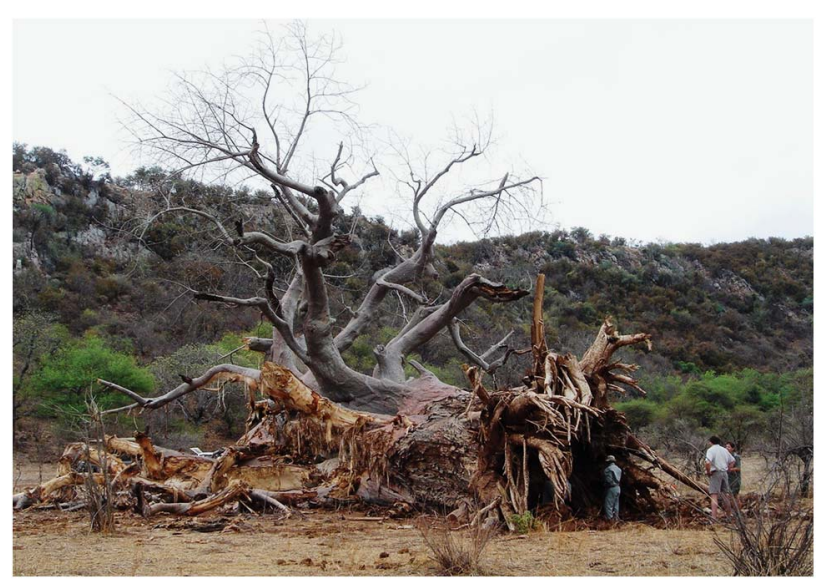

Figure 1 General view of the Pafuri Outpost baobab, which fell over and died in 2008, in the Pafuri section of the Kruger National Park, South Africa.
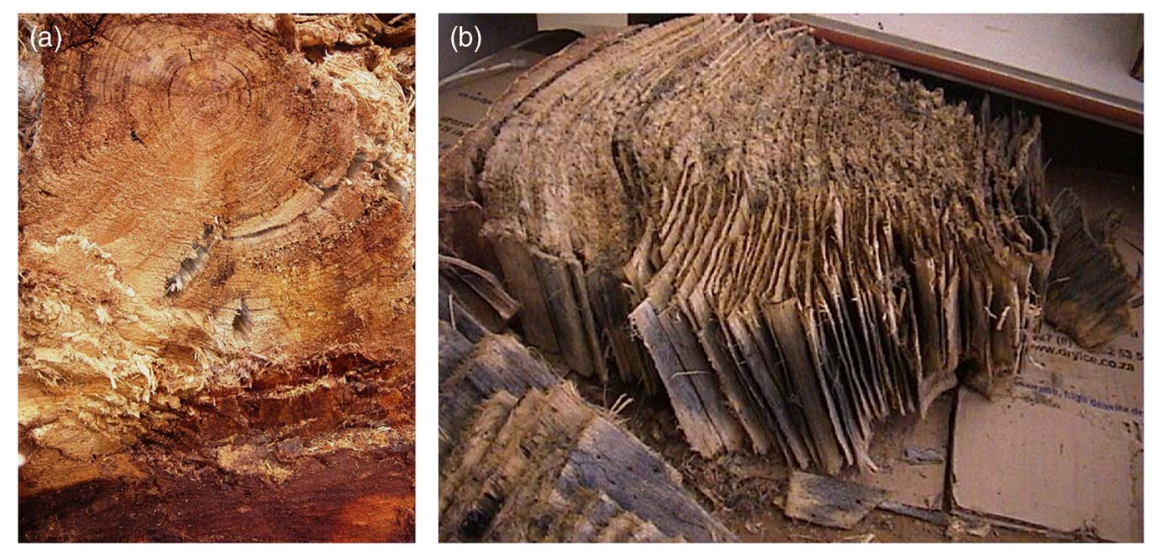

Figure 2 Details of samples collected from the fallen Pafuri Outpost baobab: (a) the large quasicomplete radial section, with the pith intact and without hollow parts, which was extracted from the trunk; (b) the individual rings, which were separated mechanically from the radial section.

six partially fused stems (Guy 1967; Pakenham 2004). Its height was $22.6 \mathrm{~m}$, the circumference $25.90 \mathrm{~m}$, and the wood volume $275 \mathrm{~m}^{3}$. Unfortunately, in January 2016, the six stems of this iconic tree, which was a symbol of Botswana, collapsed to the ground and died (Figure 3).

Die Dorslandboom (in Afrikaans, i.e. "the Thirstland tree") (south of Khaudum NP, Otjozondjupa, Namibia; $19^{\circ} 18.061^{\prime} \mathrm{S}, 020^{\circ} 39.636^{\prime} \mathrm{E}, 1132 \mathrm{~m}, 468 \mathrm{~mm}$ ) is another historic tree (Watson 2007; Stutchbury 2013). It has a height of $14.3 \mathrm{~m}$, a circumference of over $25 \mathrm{~m}$ (which cannot be measured exactly), and a wood volume of $\sim 150 \mathrm{~m}^{3}$. With its eight toppled or standing knitted stems, some of them broken and a few regenerated with new shoots, Dorslandboom can be considered a kind of "Schrödinger's baobab," which is at the same time dead and alive. Two stems collapsed before 1880 , but their remains are still alive. One leaning stem is also alive, while three stems toppled and new young branches grew at the ends of broken stems. The largest stem, which consisted in reality of two fused stems, toppled and died in 2006. 


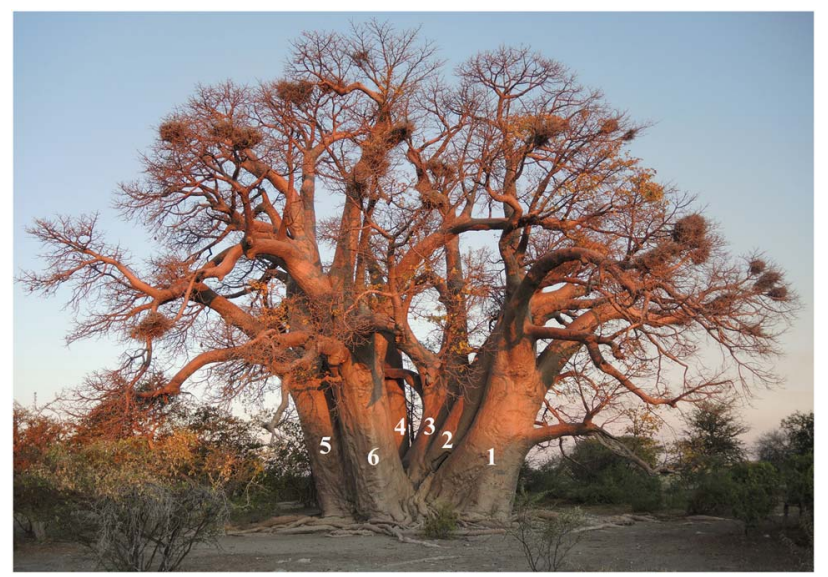

Figure 3 The Chapman baobab, the historic landmark tree of the Makgadikgadi salt pans of Botswana, is a typical example for the open ring-shaped structure. Its six main stems, which are numbered in the picture, were fused only at the base. In 2016, the six stems toppled and died.

The historic Leydsdorp baobab (Gravelotte, Mpumanalanga, South Africa; $23^{\circ} 57.427^{\prime} \mathrm{S}$, $30^{\circ} 34.509^{\prime} \mathrm{E}, 565 \mathrm{~m}, 357 \mathrm{~mm}$ ) has a height of $21.0 \mathrm{~m}$, a circumference at breast height of $19.20 \mathrm{~m}$, and a wood volume of $230 \mathrm{~m}^{3}$ (Pakenham 2004). It possesses a closed ring-shaped structure with a false cavity inside. The ring consists of three perfectly fused stems that close the false cavity (Figure 4).

Gouye Ndiouly (in Wolof, i.e. "baobab of the circumcised") (Kahone, Kaolack, Senegal; $\left.14^{\circ} 09.372^{\prime} \mathrm{N}, 016^{\circ} 01.644^{\prime} \mathrm{W}, 46 \mathrm{~m}, 496 \mathrm{~mm}\right)$ might be the oldest baobab of Senegal and in the Northern Hemisphere, as well (Figure 5). Kahone is the old capital of the Saloum Kingdom. From 1593 to 1939, the 49 kings of the Guelewares Dynasty have been enthroned under this historic baobab. This was also a site for education of the circumcised. Gouye Ndiouly toppled sometime in the past. Several fallen old stems generated an amorphous mass, out of which five new stems had emerged. Only one toppled stem, which lies horizontally, had survived and three new shoots/stems grew at the end of its broken part. Today, the reconstructed baobab has a height of $16.0 \mathrm{~m}$, a restored circumference of $14.40 \mathrm{~m}$, and a volume close to $80 \mathrm{~m}^{3}$.

\section{Sample Collection}

Large samples were collected from the two fallen single-stemmed baobabs. These were radial sections, from the outermost rings (adjacent to the bark) to the innermost rings (pith), which were found to be intact, without hollow parts. These sections were large enough to separate individual growth rings. For ring separation, a thin stainless steel spatula was inserted between the rings. The separated individual rings fell apart from one another. Several individual rings were processed and investigated by radiocarbon dating.

For the four standing and live multistemmed baobabs, several samples were collected from their inner cavities and/or from different areas of the trunk, by using Haglöf increment borers (0.60-1.00 m length, 0.00515-0.012 m inner diameter). A number of tiny pieces/segments were extracted from predetermined positions/distances along each sample. 


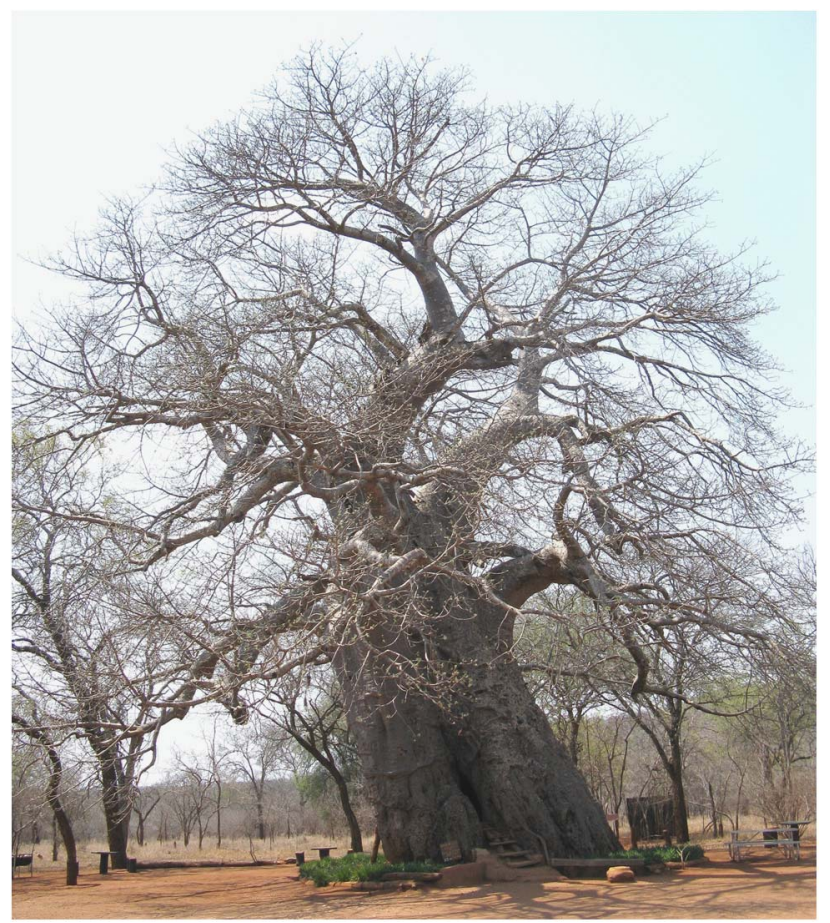

Figure 4 The leaning Leydsdorp baobab has a closed ring-shaped structure, defined by three perfectly fused stems, that close a false cavity; the cavity was used in the past as a bar. The old tree rises solitary in Mpumanalanga, South Africa.

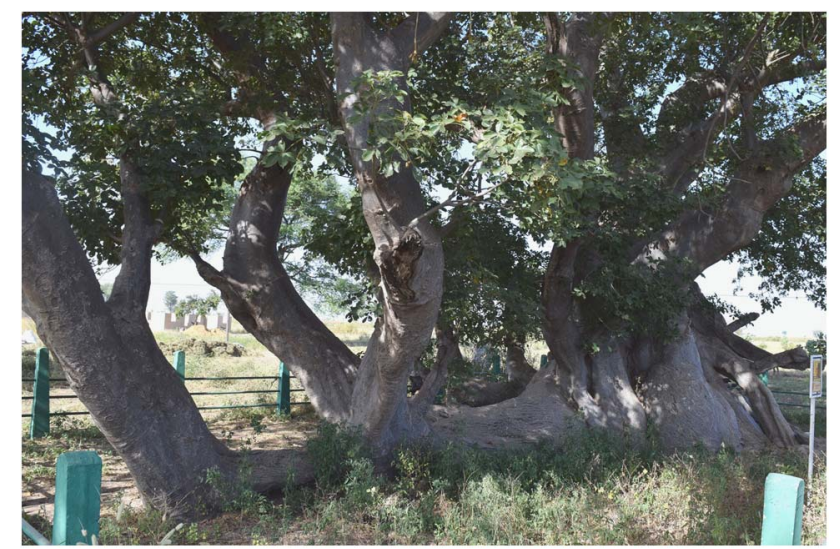

Figure 5 The historic Gouye Ndiouly from Kahone, the old capital of the Saloum Kingdom, as it looks today. One can notice the only surviving old stem, which lies horizontally, and the new shoots that emerged from the remains of the fallen stems.

\section{Sample Preparation}

Individual rings from the two fallen single-stemmed baobabs selected for ${ }^{14} \mathrm{C}$ dating were converted to $\alpha$-cellulose (Loader et al. 1997). For segments extracted for dating from samples collected from the four standing multistemmed baobabs, the standard acid-base-acid (ABA) 
pretreatment method (Olsson 1986; Patrut et al. 2010a) was used for removing soluble and mobile organic components.

The pretreated samples, which originate from the six baobabs, were finally reduced to graphite (Vogel et al. 1984). The resulting graphite samples were ${ }^{14} \mathrm{C}$ dated.

\section{Radiocarbon Measurements}

The $\mathrm{CO}_{2}$ derived from combustion of the Pafuri Outpost baobab samples was ${ }^{14} \mathrm{C}$ dated at QUADRU (Quaternary Research Unit), Pretoria, South Africa, by the gas proportional counting (GPC) technique. The graphite samples that originate from the Leokwe-A baobab were investigated by AMS ${ }^{14} \mathrm{C}$ dating at the Beta Analytic Radiocarbon Dating Laboratory, Miami, USA.

The AMS ${ }^{14} \mathrm{C}$ investigation of the graphite samples that originate from the other four baobabs was performed at the NOSAMS Facility of the Woods Hole Oceanographic Institution, Woods Hole, MA, USA, using a Pelletron tandem 500kV AMS system (Povinec et al. 2009; Roberts et al. 2010). The obtained fraction modern values corrected for isotope fractionation were ultimately converted to a ${ }^{14} \mathrm{C}$ date.

\section{Calibration}

${ }^{14} \mathrm{C}$ dates were calibrated and converted into calendar ages with OxCal v 4.2 software for Windows (Bronk Ramsey 2009), by using the IntCal13 atmospheric data set (Reimer et al. 2013) for Gouye Ndiouly located in the Northern Hemisphere, and the SHCal13 atmospheric data set (Hogg et al. 2013) for the other baobabs, which are located in the Southern Hemisphere.

\section{RESULTS AND DISCUSSION}

\section{Radiocarbon Dates and Calibrated Ages}

The ${ }^{14} \mathrm{C}$ dates and calibrated ages of the dated rings and samples are listed in Table 1 . The ${ }^{14} \mathrm{C}$ dates and errors were rounded to the nearest year. The $1 \sigma$ probability distribution $(68.2 \%)$ was selected to derive calibrated age ranges. For three samples, the $1 \sigma$ distribution is consistent with one range of calendar years. For six samples, the $1 \sigma$ distribution corresponds to two ranges, for two samples to three ranges, while for the other three cases it is consistent with four ranges. For these 11 samples, the confidence interval of one range is considerably greater than that of the others and this range is usually consistent with the age sequence along the corresponding sample; therefore, it was selected as the cal AD range of the sample (marked in bold) for the purpose of this discussion. For obtaining single age values, which correspond each to an assigned year, we derived a mean value for the 14 selected age ranges; this mean value divides the range into two equal areas.

We would like to stress that the use of $\mathrm{AMS}{ }^{14} \mathrm{C}$ dating in tree research, for determining ages, growth rates, architectures or ring frequencies of large and/or old trees, as well as its use in climate research, for determining age sequences prior to the stable isotope analysis, requires mandatory single age values or assigned years for each ${ }^{14} \mathrm{C}$ date. Finally, for three samples, which correspond to a depth of $0.5-1 \mathrm{~cm}$ into the wood, practically the outermost rings that are adjacent to the external/outer bark (or to the innermost rings adjacent to the cavity bark, for samples collected from false cavities), the fraction modern values were greater than $1\left(\mathrm{~F}_{\mathrm{m}}>1\right)$. Such values, with fraction modern greater than 1 , correspond to negative ${ }^{14} \mathrm{C}$ dates and are termed greater than Modern (> Modern). The high negative ${ }^{14} \mathrm{C}$ dates cannot be calibrated with 
Table 1 Radiocarbon dating results and calibrated ages of rings isolated from toppled single-stemmed baobabs and of samples collected from standing or toppled multistemmed baobabs

\begin{tabular}{|c|c|c|c|c|c|c|c|}
\hline Tree & Ring $^{1}$ & $\begin{array}{l}\text { Sample } \\
\text { code }\end{array}$ & $\begin{array}{l}\text { Depth }^{2} \\
\left(10^{-2} \mathrm{~m}\right)\end{array}$ & $\begin{array}{l}{ }^{14} \mathrm{C} \text { date } \\
\text { [error] } \\
\left({ }^{14} \mathrm{C} \text { yr BP }\right) \\
\left\{{ }^{14} \mathrm{C} \text { activity }\right\}\end{array}$ & $\begin{array}{l}\text { cal AD range } \\
1 \sigma \\
\text { [confidence interval] }\end{array}$ & $\begin{array}{l}\text { Assigned year } \\
\text { [error] } \\
\text { (cal AD) }\end{array}$ & Accession \# \\
\hline \multirow[t]{2}{*}{ Pafuri Outpost } & 40 & - & - & $412[ \pm 20]$ & $\begin{array}{c}\mathbf{1 4 6 0}-\mathbf{1 4 9 9}[\mathbf{5 4 . 3 \%} \mathbf{0} \\
1598-1610[13.9 \%]\end{array}$ & $\begin{array}{l}1480 \\
{[+19,-20]}\end{array}$ & Pta-9814 \\
\hline & $\begin{array}{l}490 \\
\text { (pith) }\end{array}$ & - & - & $1000[ \pm 20]$ & $\begin{array}{l}1034-1048[13.8 \%] \\
\mathbf{1 0 8 4}-\mathbf{1 1 3 9}[\mathbf{5 4 . 4 \%} \%\end{array}$ & $\begin{array}{l}1112 \\
{[+27,-28]}\end{array}$ & Pta-9797 \\
\hline \multirow[t]{2}{*}{ Leokwe-A } & 15 & - & - & $280[ \pm 30]$ & $\begin{array}{l}\mathbf{1 6 2 9 - 1 6 7 0}[\mathbf{5 6 . 0 \%}] \\
1748-1755[4.0 \%] \\
1783-1795[8.2 \%]\end{array}$ & $\begin{array}{l}1652 \\
{[+18,-23]}\end{array}$ & Beta-378949 \\
\hline & $\begin{array}{l}678 \\
\text { (pith) }\end{array}$ & - & - & $880[ \pm 30]$ & $\begin{array}{l}\mathbf{1 1 7 7}-\mathbf{1 2 3 0}[\mathbf{6 3 . 0 \%} \mathbf{0} \\
1252-1260[5.2 \%]\end{array}$ & $\begin{array}{l}1208 \\
{[+22,-31]}\end{array}$ & Beta-378952 \\
\hline \multirow[t]{5}{*}{ Leydsdorp } & - & LEY-1a & 1 & $212[ \pm 24]$ & $\begin{array}{l}1669-1678[8.8 \%] \\
\mathbf{1 7 3 3 - 1 7 8 6}[\mathbf{5 3 . 0 \%}] \\
1794-1800[6.4 \%]\end{array}$ & $\begin{array}{l}1760 \\
{[+26,-27]}\end{array}$ & OS-87713 \\
\hline & - & LEY-1c & 45 & $990[ \pm 30]$ & $\begin{array}{l}1040-1052[9.8 \%] \\
\mathbf{1 0 7 9 - 1 1 4 6}[\mathbf{5 8 . 4 \%}]\end{array}$ & $\begin{array}{l}1114 \\
{[+32,-35]}\end{array}$ & OS-87715 \\
\hline & 一 & LEY-2a & 1 & $146[ \pm 31]$ & $\begin{array}{l}1696-1725[14.3 \%] \\
1808-1817[4.6 \%] \\
\mathbf{1 8 2 8}-\mathbf{1 8 9 4}[\mathbf{3 2 . 2} \%] \\
1920-\ldots[17.1 \%]\end{array}$ & $\begin{array}{l}1860 \\
{[+34,-32]}\end{array}$ & OS-72143 \\
\hline & - & LEY-11a & 0.5 & $\{>$ Modern $\}$ & - & - & OS-90689 \\
\hline & - & LEY-11b & 50 & $496[ \pm 27]$ & $1430-1454[68.2 \%]$ & $\begin{array}{l}1443 \\
{[+11,-13]}\end{array}$ & OS-76796 \\
\hline \multirow[t]{3}{*}{ Chapman } & - & $\mathrm{CH}-1 \mathrm{a}$ & 0.5 & $\{>$ Modern $\}$ & - & - & OS-90741 \\
\hline & - & $\mathrm{CH}-3 \mathrm{a}$ & 0.5 & $148[ \pm 24]$ & $\begin{array}{l}1697-1724[15.0 \%] \\
1808-1816[4.3 \%] \\
\mathbf{1 8 3 0}-\mathbf{1 8 9 2}[\mathbf{3 3 . 7 \%}] \\
1922-1950[15.2 \%]\end{array}$ & $\begin{array}{c}1861 \\
{[ \pm 31]}\end{array}$ & OS-90735 \\
\hline & - & $\mathrm{CH}-3 \mathrm{x}$ & close to pith & $1381[ \pm 22]$ & $654-681[63.0 \%]$ & 669 & OS-95069 \\
\hline
\end{tabular}




\begin{tabular}{|c|c|c|c|c|c|c|c|}
\hline Tree & Ring $^{1}$ & $\begin{array}{l}\text { Sample } \\
\text { code }\end{array}$ & $\begin{array}{l}\text { Depth }^{2} \\
\left(10^{-2} \mathrm{~m}\right)\end{array}$ & $\begin{array}{l}{ }^{14} \mathrm{C} \text { date } \\
\text { [error] } \\
\left({ }^{14} \mathrm{C} \text { yr BP }\right) \\
\left\{{ }^{14} \mathrm{C} \text { activity }\right\}\end{array}$ & $\begin{array}{l}\text { cal AD range } \\
1 \sigma \\
\text { [confidence interval] }\end{array}$ & $\begin{array}{l}\text { Assigned year } \\
\text { [error] } \\
\text { (cal AD) }\end{array}$ & Accession \# \\
\hline \multirow{4}{*}{ Dorslandboom } & & & & & $749-752[5.2 \%]$ & {$[+12,-15]$} & \\
\hline & - & $\mathrm{CH}-4 \mathrm{a}$ & 0.5 & $\{>$ Modern $\}$ & - & - & OS-95071 \\
\hline & - & D-11a & 0.5 & $635[ \pm 16]$ & $1324-1343[50.9 \%]$ & 1333 & OS-125225 \\
\hline & - & D-11x & close to pith & $1956[ \pm 21]$ & $\begin{array}{c}1390-1396[18.3 \%] \\
\mathbf{6 6}-\mathbf{1 1 6}[\mathbf{6 8 . 2 \%} \%\end{array}$ & $\begin{array}{c}{[+9,-10]} \\
93 \\
{[+23,-27]}\end{array}$ & OS-87470 \\
\hline \multirow[t]{2}{*}{ Gouye Ndiouly } & - & GN-1a & 0.1 & $115[ \pm 25]$ & $\begin{array}{l}1690-1710[10.6 \%] \\
1718-1728[5.9 \%] \\
\mathbf{1 8 1 0}-\mathbf{1 8 9 0}[\mathbf{4 3 . 6 \%}] \\
1910-1925[8.1 \%]\end{array}$ & {$[+38,-42]$} & OS-90737 \\
\hline & - & GN-1b & 60 & $833[ \pm 25]$ & $1185-1248[68.2 \%]$ & $\begin{array}{l}1215 \\
{[+33,-30]}\end{array}$ & OS-90734 \\
\hline
\end{tabular}

${ }^{1}$ The rings are counted in reverse order.

${ }^{2}$ Depth in the wood from the sampling point. 
the standard calibration curves. In such cases, the dated wood of trees is young, being formed after AD 1950. We were not interested in calibrating the fraction modern by using (post)bomb curves; we only considered that the growth in the respective stems was still active.

\section{Growth Stop}

Pafuri Outpost was the first baobab for which the growth stop phenomenon was identified. The inner part of this single-stemmed baobab, which toppled in 2008, was found to be intact and without hollow parts in the stem. Therefore, it was possible to collect a sample for dating right from the pith. Its ${ }^{14} \mathrm{C}$ date was $1000 \pm 20 \mathrm{BP}$, which corresponds to a calibrated age close to $900 \mathrm{yr}$; the assigned year is AD $1112(+27,-28)$. We collected a large radial section, from which we separated 434 individual growth rings (out of 490 rings of the stem), much more than expected. Ring 40 (rings are counted in reversal order, from the youngest to the oldest) was found to have a ${ }^{14} \mathrm{C}$ date of $412 \pm 20 \mathrm{BP}$; the assigned year for this value is AD $1480(+19,-20)$. The result indicates that the baobab stopped growing around AD 1520, when it was $410 \mathrm{yr}$ old, but it stayed alive until AD 2008, continuing to produce leaves, flowers, and pods.

Leokwe-A was another single-stemmed African baobab that fell over between 2003 and 2008 and was found to be relatively intact. A large radial section was collected from its stem, out of which individual growth rings were isolated. The ${ }^{14} \mathrm{C}$ date of its pith (ring 678, in reverse order) was $880 \pm 30 \mathrm{BP}$, which corresponds to a calibrated age close to $800 \mathrm{yr}$ when the tree died; the assigned year is $\mathrm{AD} 1208(+22,-31)$. One of the outermost rings, i.e. ring 15 , was ${ }^{14} \mathrm{C}$ dated to $280 \pm 30 \mathrm{BP}$; the assigned year is AD $1652(+18,-23)$. According to this result, the Leokwe-A baobab stopped growing around AD 1670, when it was $560 \mathrm{yr}$ old.

The single-stemmed baobabs were also sectioned across the whole stem; both show evidence of growth stop around the full circumference and neither showed any indication of asymmetry that would accommodate hundreds of missing rings. We suspect that both baobabs stopped growing due to stress, triggered by the change of climate factors during the Little Ice Age, which was cold and very dry in southern Africa (Woodborne et al. 2015, 2016).

As mentioned, the vast majority of large and old baobabs are multistemmed. This fact is due to the ability of baobabs to produce new stems during their lifecycle, such as other tree species produce branches. For these trees, the growth may stop for the oldest stems, usually after the age of $1000 \mathrm{yr}$. We exemplify our statement by presenting the growth stop for several very old African baobab specimens, such as Chapman and Dorslandboom.

The historic Chapman baobab had an open ring-shaped structure, defined by six main stems that were fused from the base up to a height of around $2 \mathrm{~m}$. According to AMS ${ }^{14} \mathrm{C}$ dating, the six stems belonged to three different generations, which were 500, 800-1000, and over $1300 \mathrm{yr}$ old. The ${ }^{14} \mathrm{C}$ activity of the outermost rings of stems 1 and 4 , corresponding to the sample segments $\mathrm{CH}-1 \mathrm{a}$ and $\mathrm{CH}-4 \mathrm{a}$, was found to be greater than Modern. On the other hand, the ${ }^{14} \mathrm{C}$ date of sample segment $\mathrm{CH}-3 \mathrm{a}$, which consists of the outermost rings of the largest and oldest stem 3, was $148 \pm 24 \mathrm{BP}$; the assigned year for this value is AD $1861( \pm 31)$. Stem 3 was the biggest and also the oldest stem of Chapman. Due to the presence of a large fire scar, it was possible to collect a sample very close to the pith of stem 3 . Its ${ }^{14} \mathrm{C}$ date was $1381 \pm 22 \mathrm{BP}$; the assigned year is AD $669(+12,-15)$. These results demonstrate that the old stem 3 stopped growing around AD 1860, while the other stems have continued their growth at a moderate rate. Nevertheless, no significant differences were found between the leaves, flowers, and pods produced by the six stems. 
The stem that survived the longest after it has stopped growing belongs to the historic Dorslandboom of Namibia. The outermost rings of this stem, which consisted in fact of two fused stems, were dated by ${ }^{14} \mathrm{C}$. The ${ }^{14} \mathrm{C}$ date of sample $\mathrm{D}-11$ a was $635 \pm 16 \mathrm{BP}$; the assigned year is $\mathrm{AD} 1333(+9,-10)$. This double stem survived the growth stop for around $675 \mathrm{yr}$, until $\mathrm{AD} 2006$, when it toppled and died at an age greater than $2000 \mathrm{yr}$. The ${ }^{14} \mathrm{C}$ date of the oldest dated sample D-11x was $1956 \pm 21 \mathrm{BP}$; the assigned year is AD $93(+23,-27)$.

The growth stop phenomenon is not limited to $A$. digitata. We reported that stems belonging to Tsitakakoike, the biggest and oldest known $A$. grandidieri, as well as to Grandmother, the oldest known $A$. rubrostipa, stopped both growing $250 \mathrm{yr}$ ago, around AD 1760 (Patrut et al. 2015b, 2015c).

Beside the climate factors and old age, we identified a third factor that may produce growth stop of baobab stems. This factor is the tendency to keep a stable internal architecture of the tree. The Lebombo Eco Trail baobab was the first specimen for which we identified the closed ringshaped structure. For samples collected from the false cavity walls, the age values increase with the distance into the wood up to a point of maximum age, after which the values decrease toward the outer part. This anomaly of age sequences is due to the fact that false cavities are only empty spaces between several fused stems disposed in a ring-shaped structure (Patrut et al. 2015a, 2015c, 2015d).

We found that for the Lebombo baobab, the five stems (with ages between 900 and $1400 \mathrm{yr}$ ) stopped growing over the past $500 \mathrm{yr}$ only toward the false cavity, which reached a highly symmetrical and very stable shape. At the same time, the five stems of Lebombo continue growing toward the outer part at a moderate rate (Patrut et al. 2015a).

Here, we present dating results of the Leydsdorp baobab, another specimen with a closed ring defined by three perfectly fused stems, which stopped growing toward the false cavity. Sample segments LEY-1a (1 cm depth in the wood) and LEY-2a $(1 \mathrm{~cm})$, collected from the false cavity, are composed of the innermost rings adjacent to the cavity walls. The ${ }^{14} \mathrm{C}$ dates of these segments, which originate from two different stems, are $212 \pm 24$ and $146 \pm 31 \mathrm{BP}$; the assigned years are AD $1760(+26,-27)$ and $\mathrm{AD} 1860(+34,-32)$. These results demonstrate that the two dated stems stopped growing toward the false cavity at different times in the past, i.e. $255 \mathrm{yr}$ (toward the west) and $155 \mathrm{yr}$ ago (toward the east). The oldest sample segment LEY-1c $(45 \mathrm{~cm})$ had a ${ }^{14} \mathrm{C}$ date of $990 \pm 30 \mathrm{BP}$; the assigned year is AD $1114(+32,-35)$.

We dated two segments extracted from sample LEY-11, which was collected from the outer part of the trunk. The ${ }^{14} \mathrm{C}$ activity of segment LEY-11a $(0.5 \mathrm{~cm})$, which includes the outermost rings, was greater than Modern, showing that the stem has continued growing toward the outer part. The ${ }^{14} \mathrm{C}$ date of segment LEY $-11 \mathrm{~b}(50 \mathrm{~cm})$ was found to be $496 \pm 27 \mathrm{BP}$; the corresponding assigned year is AD $1443(+11,-13)$. Dating samples collected from the outer part of other stems produced comparable results. Such values reveal that the stems of Leydsdorp baobab grew toward the outer part by $0.50 \mathrm{~m}$ over the past $570 \mathrm{yr}$. Thus, in the case of the Leydsdorp baobab, the three stems stopped growing over the past 155-255 yr only toward the false cavity that reached a stable shape, which compensates the significant lean of the tree (around $20-25^{\circ}$ toward the west). The relatively tall false cavity $(4.80 \mathrm{~m})$ has a roughly triangular base and its roof is slightly rounded. Had the stems continued growing toward the cavity, this would have affected its stability and the baobab would have collapsed. 
Finally, we mention an additional factor that may induce growth stop. This factor is a major trauma suffered by baobab stems. Such a case is the collapse of one or several stems that survived this event, but stopped growing. We investigated the only one remaining toppled stem of Gouye Ndiouly, which survived the major collapse of the baobab. Sample GN-1a, which consists of the outermost rings, had a ${ }^{14} \mathrm{C}$ date of $115 \pm 25 \mathrm{BP}$; the assigned year is AD $1852(+38,-42)$. This value suggests that the surviving stem stopped growing around AD 1850, which is very probably the point in time when the historic baobab toppled. The oldest remaining wood of this stem, represented by sample GN-1b, was ${ }^{14} \mathrm{C}$ dated to $833 \pm 25 \mathrm{BP}$; the assigned year is $\mathrm{AD} 1215(+33,-30)$. Because some parts of this fallen stem are missing, we estimate that its age in the presumptive pith would have been close to $1000 \mathrm{yr}$.

We identified a new and unexpected phenomenon, which seems to be specific only to baobab trees, i.e. to tree species belonging to the Adansonia genus: the growth stop. The growth stop may affect the whole tree or only its oldest or its severely impacted stem(s). Under this condition, the affected baobabs may survive for several centuries, continuing to produce leaves, flowers, and fruits.

The growth stop can be associated with the fact that baobabs are the only known trees that survive when the bark is stripped off around the full circumference of the trunk/stem. This is a common practice of the local population in many parts of Africa; the locals may remove not only the bark, but also several centimeters of wood adjacent to the bark. This unique feature is a consequence of the fact that, during the rainy season, baobabs transport water and nutrients through the entire volume of their trunks/stems rather than only through the youngest outermost rings.

The baobab's trunk/stem, which contains a high number of parenchyma cells, stores water during the rainy season and swells, increasing its girth. The baobab wood has a very high water content, up to $79 \%$ by mass (Chapotin et al. 2006). This large reservoir of water is used partially during the dry season and allows the baobab to survive many years of severe drought. When using the stored water, the trunk/stem shrinks gradually, decreasing its girth. The variations of the baobab's girth, according to its water content, are independent from the proper growth, which consists in the production of new wood under the form of rings. The capacity of baobabs to store large amounts of water in their trunks/stems allows the trees belonging to the Adansonia genus to survive in a good state of vegetation even after the growth stop.

For multistemmed baobabs with the more or less fused and erect stems, we found only minor differences $(<5 \%)$ between the water content of the old stem(s) that stopped growing hundreds of years ago and the water content of younger stems that continue to grow. On the other hand, for the same stem(s) that stopped growing, we found significant differences (up to $15 \%$ ) between the water content during the rainy season and in the dry season. These results indicate that the water transport in old stems of baobabs is not significantly affected by the growth stop and is not concentrated in the outer rings. They also suggest that the known mechanisms of water transport in trees does not seem to apply to baobabs.

\section{CONCLUSIONS}

This research describes the growth stop, a newly reported phenomenon, which appears to be specific only to baobabs, i.e. to trees that belong to the Adansonia genus. We found several 
anomalies while performing a complex ${ }^{14} \mathrm{C}$ investigation of samples collected from large and old baobabs, for determining their age, growth, and architecture. Thus, in some cases, the outermost rings of baobabs, which were close to the bark, were found to be old, with ages of several hundreds of years, instead of being very young. The only reasonable explanation for this anomaly is the fact that the trunk/stems of these baobabs stopped growing; however, they remained alive for centuries.

${ }^{14} \mathrm{C}$ dating results of six baobabs were disclosed and discussed. Two of these are single-stemmed specimens (Pafuri Outpost, Leokwe-A), which died recently. The other four baobabs are multistemmed and alive (Chapman, Dorslandboom, Leydsdorp, Gouye Ndiouly), with the exception of one specimen (Chapman), which toppled and died in 2016. For multistemmed baobabs, the growth stop may affect only one or several stems.

We identified four factors that may determine the growth stop. These factors are (i) stress induced by severe climate conditions (Pafuri Outpost and Leokwe-A stopped growing in AD 1520 and 1670, during the Little Ice Age, but they stayed alive until AD 2008 and 2003-2008); (ii) old age (the oldest stem of Chapman stopped growing around AD 1860 and survived until AD 2016, while the oldest double stem of Dorslandboom stopped growing around AD 1370 and survived until AD 2008); (iii) the need to preserve a stable internal architecture (the stems of Leydsdorp stopped growing sequentially toward the false cavity between 1760 and 1860 , but they continued to grow toward the outer part of the leaning trunk); (iv) the collapse of a stem that survives this traumatic event (the old stems of the historic Gouye Ndiouly toppled around AD 1850; the only surviving stem stopped growing at that time and new shoots emerged from its broken part).

The baobabs and their stems affected by growth stop may survive for several centuries, continuing to produce leaves, flowers, and fruit. The growth stop phenomenon was associated with the capacity of baobabs to store during the rainy season large amounts of water in their trunks/ stems. This reservoir of water is used in the dry season and allows baobabs to survive periods of severe and prolonged drought.

The obtained results also suggest a very special mechanism of water transport in trees belonging to the Adansonia genus. Additional work is needed to understand the processes that move water in baobab wood.

\section{ACKNOWLEDGMENTS}

The investigation and collection of samples from the trees was approved and authorized by The South African National Parks, The Kruger National Park, The Mapungubwe National Park, The Ministry of Environment and Tourism of Namibia, The Ministry of Environment and Protection of Nature of Senegal, and The Direction of National Parks of Senegal. Special thanks to Ralph Bousfield, Steve Bolnick, and Michael Turner for facilitating the investigation and sampling of baobabs. The authors thank Diana Mayne for assistance and helpful discussions. The research was funded by the Romanian Ministry of National Education CNCSUEFISCDI under grant PN-II-ID-PCE-2013-76. The AMS ${ }^{14} \mathrm{C}$ investigations of Chapman, Dorslandboom, Leydsdorp, and Gouye Ndiouly were performed at the NOSAMS Facility of the Woods Hole Oceanographic Institution. AMS ${ }^{14} \mathrm{C}$ dating and fieldwork on Leokwe-A were supported by the African Origins Platform of the National Research Foundation of South Africa (Grant Number 82596). 


\section{REFERENCES}

Baum DA. 1995. A systematic revision of Adansonia (Bombacaceae). Annals of the Missouri Botanical Garden 82:440-71.

Baum DA. 1996. The ecology and conservation of the baobabs of Madagascar. Primate Report 46:311-27.

Bronk Ramsey C. 2009. Bayesian analysis of radiocarbon dates. Radiocarbon 51(1):337-60.

Chapotin SM, Razanameharizaka JH, Holbrook NM. 2006. A biomechanical perspective on the role of large stem volume and high water content in baobab trees (Adansonia spp.; Bombacaceae). American Journal of Botany 93(9):1251-64.

Guy GL. 1967. Notes on some historic baobabs. Rhodesiana 16:17-26.

Guy GL. 1970. Adansonia digitata and its rate of growth in relation to rainfall in south central Africa. Proceedings \& Tranasactions, Rhodesia Scientific Association, Salisbury 54(2):68-84.

Hogg AG, Hua Q, Blackwell PG, Niu M, Buck CE, Guilderson TP, Heaton TJ, Palmer JG, Reimer PJ, Reimer RW, Turney CSM, Zimmerman SRH. 2013. SHCal13 Southern Hemisphere calibration, 0-50,000 years cal BP. Radiocarbon 55(4):1889-903.

Loader NJ, Robertson I, Barker AC, Switsur VR, Waterhouse JS. 1997. An improved technique for the batch processing of small wholewood samples to $\alpha$-cellulose. Chemical Geology 136(3):313-7.

Olsson IU. 1986. Radiometric methods. In: Berglung B, editor. Handbook of Holocene Palaeoecolgy and Palaeohydrology. Chichester: Wiley. p 273-312.

Pakenham T. 2004. The Remarkable Baobab. London: Weidenfield \& Nicholson.

Patrut A, von Reden KF, Lowy DA, Alberts AH, Pohlman JW, Wittmann R, Gerlach D, Xu L, Mitchell CS. 2007. Radiocarbon dating of a very large African baobab. Tree Physiology 27:1569-74.

Patrut A, von Reden KF, Lowy DA, Mayne DH, Elder KE, Roberts ML, McNichol AP. 2010a. Comparative AMS radiocarbon dating of pretreated versus non-pretreated wood samples. Nuclear Instruments and Methods in Physics Research B 268(7-8):910-3.

Patrut A, Mayne DH, von Reden KF, Lowy DA, Van Pelt R, McNichol AP, Roberts ML, Margineanu D. 2010b. Fire history of a giant African baobab evinced by radiocarbon dating. Radiocarbon 52(2-3):717-26.

Patrut A, Mayne DH, von Reden KF, Lowy DA, Venter S, McNichol AP, Roberts ML, Margineanu D. 2010c. Age and growth rate dynamics of an old African baobab determined by radiocarbon dating. Radiocarbon 52(2-3):727-34.

Patrut A, von Reden KF, Van Pelt R, Mayne DH, Lowy DA, Margineanu D. 2011. Age determination of large live trees with inner cavities: radiocarbon dating of Platland tree, a large African baobab. Annals of Forest Science 68: 993-1003.

Patrut A, von Reden KF, Mayne DH, Lowy DA, Patrut RT. 2013. AMS radiocarbon investigation of the African baobab: searching for the oldest tree. Nuclear Instruments and Methods in Physics Research B 294:622-6.

Patrut A, Woodborne S, von Reden KF, Hall G, Hofmeyr M, Lowy DA, Patrut RT. 2015a. African baobabs with false inner cavities: the radiocarbon investigation of the Lebombo Eco Trail baobab. PLOS ONE 10(1):e0117193.

Patrut A, von Reden KF, Danthu P, Leong Pock-Tsy J-M, Patrut RT, Lowy DA. 2015b. Searching for the oldest baobab of Madagascar: radiocarbon investigation of large Adansonia rubrostipa trees. PLoS ONE 10(3): e0121170.

Patrut A, von Reden KF, Danthu P, Leong PockTsy J-M, Rakosy L, Patrut RT, Lowy DA, Margineanu D. 2015c. AMS radiocarbon dating of very large Grandidier's baobabs (Adansonia grandidieri). Nuclear Instruments and Methods in Physics Research B 361:591-8.

Patrut A, Woodborne S, Patrut RT, Hall G, Rakosy L, von Reden KF, Lowy DA, Margineanu D. 2015d. Radiocarbon dating of African baobabs with two false inner cavities: the investigation of Luna Tree. Studia UBB Chemia 50(4):7-20.

Patrut A, Patrut RT, Danthu P, Leong Pock-Tsy J-M, Rakosy L, Lowy DA, von Reden KF. 2016. AMS radiocarbon dating of Large $\mathrm{Za}$ baobabs (Adansonia za) of Madagascar. PLoS ONE 11(1):e0146977.

Pettigrew JD, Bell LK, Bhagwandin A, Grinan E, Jillani N, Meyer J, Waybuyele E, Vickers CE. 2013. Morphology, ploidy and molecular phylogenetics reveal a new diploid species from Africa in the baobab genus Adansonia (Malvaceae; Bombacoideae). Taxon 61:1240-50.

Povinec PP, Litherland AE, von Reden KF. 2009. Developments in radiocarbon technologies: from the Libby counter to compound-specific AMS analyses. Radiocarbon 51(1):45-78.

Reimer PJ, Bard E, Bayliss A, Beck JW, Blackwell PG, Bronk Ramsey C, Buck CE, Cheng H, Lawrence Edwards R, Friedrich M, Grootes PM, Guilderson TP, Haflidason H, Hajdas I, Hatté C, Heaton TJ, Hoffmann DL, Hogg AG, Hughen KA, Kaiser KF, Kromer B, Manning SW, Niu M, Reimer RW, Richards DA, Scott EM, Southon JR, Staff RA, Turney CSM, van der Plicht J. 2013. IntCal13 and Marine13 radiocarbon age calibration curves, $0-50,000$ years cal BP. Radiocarbon 55(4):1869-87.

Roberts ML, Burton JR, Elder KL, Longworth $\mathrm{BE}$, McIntyre $\mathrm{CP}$, von Reden KF, Han BX, Rosenheim BE, Jenkins WE, Galutschek E, McNichol AP. 2010. A high-performance ${ }^{14} \mathrm{C}$ accelerator 


\section{A Patrut et al.}

mass spectrometry system. Radiocarbon 52(2): 228-35.

Robertson I, Loader NJ, Froyd CA, Zambatis N, Whyte I, Woodborne S. 2006. The potential of the baobab (Adansonia digitata L.) as a proxy climate archive. Applied Geochemistry 21(10):1674-80.

Stutchbury R. 2013. The Baobab. Harare: Camera Africa.

Vogel JS, Southon JR, Nelson DE, Brown TA. 1984. Performance of catalytically condensed carbon for use in accelerator mass-spectrometry. Nuclear Instruments and Methods in Physics Research B 5(2):289-93.

Watson R. 2007. The African Baobab. Cape Town: Struik.
Wickens GE. 1983. The baobab: Africa's upsidedown tree. Kew Bulletin 47:173-209.

Wickens GE, Lowe P. 2008. The Baobabs: Pachycauls of Africa, Madagascar and Australia. Dordrecht: Springer.

Woodborne S, Hall G, Robertson I, Patrut A, Rouault M, Loader NJ, Hofmeyr M. 2015. A 1000 -year carbon isotope rainfall proxy record from South African baobab trees (Adansonia digitata L.). PLoS ONE 10(5):e0124202.

Woodborne S, Gandiwa P, Hall G, Patrut A, Finch J. 2016. A regional carbon isotope dendro-climatology from the South African summer rainfall area. PLoS ONE 11(7): e0159361. 